\title{
Comparison of emergence agitation between sevoflurane/ nitrous oxide administration and sevoflurane administration alone in children undergoing adenotonsillectomy with preemptive ketorolac
}

\author{
Ji Hye Park, Byung Gun Lim, Hee Zoo Kim, Myoung Hoon Kong, Sang Ho Lim, Nan Suk Kim, and \\ Il Ok Lee
}

Department of Anesthesiology and Pain Medicine, Korea University Guro Hospital, Korea University College of Medicine, Seoul, Korea

Background: Sevoflurane anesthesia commonly causes emergence agitation (EA) in children. One previous study has reported that the use of nitrous oxide $\left(\mathrm{N}_{2} \mathrm{O}\right)$ during the washout of sevoflurane may reduce EA by decreasing the residual sevoflurane concentration, while many animal studies suggest that $\mathrm{N}_{2} \mathrm{O}$ poses a potential risk to children. The present study was designed to compare EA in children assigned to receive sevoflurane with $\mathrm{N}_{2} \mathrm{O}$ (group $\mathrm{N}$ ) or sevoflurane alone (group S).

Methods: We enrolled 80 children aged 3-10 years. Anesthesia was induced with $5 \mathrm{mg} / \mathrm{kg}$ thiopental sodium, $0.6 \mathrm{mg} / \mathrm{kg}$ rocuronium and $0.5 \mathrm{mg} / \mathrm{kg}$ ketorolac, and was maintained with $50 \% \mathrm{~N}_{2} \mathrm{O}$ and sevoflurane in group $\mathrm{N}$ or with sevoflurane alone in group S. The sevoflurane concentration was adjusted with a bispectral index (BIS) of 40-60. After completion of the surgery, $\mathrm{N}_{2} \mathrm{O}$ and sevoflurane were simultaneously discontinued and replaced with oxygen $\left(\mathrm{O}_{2}\right)$ at $6 \mathrm{~L} / \mathrm{min}$. End-tidal sevoflurane concentration (Et Sevo) (\%), BIS at the end of surgery, Et Sevo at recovery of self-respiration and emergence profiles were recorded. EA occurrence, pain score and rescue fentanyl consumption were assessed in the postanesthesia care unit.

Results: Et Sevo was significantly lower in group N (1.9\%) than in group S (2.3\%) at the end of surgery. However, there were no differences in Et Sevo at recovery of self-respiration, emergence times, the incidence of EA, pain score or dose of rescue fentanyl between the groups.

Conclusions: In children undergoing adenotonsillectomy with preemptive ketorolac, anesthetic maintenance using sevoflurane alone does not affect the incidence of EA or emergence profiles compared to anesthetic maintenance using sevoflurane with $\mathrm{N}_{2} \mathrm{O}$. (Korean J Anesthesiol 2014; 66: 34-38)

Key Words: Emergence agitation, Nitrous oxide, Sevoflurane, Tonsillectomy and adenoidectomy.

Received: June 11, 2013. Revised: 1st, July 3, 2013; 2nd, July 24, 2013; 3rd, July 26, 2013. Accepted: July 26, 2013.

Corresponding author: Il Ok Lee, M.D., Department of Anesthesiology and Pain Medicine, Korea University Guro Hospital, Korea University College of Medicine, 148, Gurodong-ro, Guro-gu, Seoul 152-703, Korea. Tel: 82-2-2626-1437, Fax: 82-2-851-9897, E-mail: iloklee@korea.ac.kr

(c) This is an open-access article distributed under the terms of the Creative Commons Attribution Non-Commercial License (http:// creativecommons.org/licenses/by-nc/3.0/), which permits unrestricted non-commercial use, distribution, and reproduction in any medium, provided the original work is properly cited. 


\section{Introduction}

Sevoflurane is an inhalation anesthetic widely used in pediatric anesthesia with minimal airway irritation. This agent has rapid induction and recovery properties due to its low blood-gas and low tissue-gas partition coefficients. However, it has been reported that emergence agitation (EA), occurring after general anesthesia in children, is more frequent after using sevoflurane [1-3]. Possible etiological factors of pediatric EA after using sevoflurane include rapid emergence, psychological and neurological immaturity of children $[4,5]$, concentration of residual sevoflurane [6] and sevoflurane-induced increase in noradrenaline release from the central nervous system [7].

Nitrous oxide $\left(\mathrm{N}_{2} \mathrm{O}\right)$, an inexpensive inhalation anesthetic with low potency, has long been used because it not only decreases the minimum alveolar concentration (MAC) of high potency inhalation anesthetics as an adjuvant, but also contributes to hemodynamic stability. Moreover, $\mathrm{N}_{2} \mathrm{O}$ has been reported to reduce EA by lowering the concentration of residual sevoflurane during emergence [6]. However, several animal studies have showed that the administration of $N$-methyl-D-aspartate (NMDA) receptor antagonists, including $\mathrm{N}_{2} \mathrm{O}$, into a developing brain caused neurotoxicity $[8,9]$. As it is suggested that a combination of $\mathrm{N}_{2} \mathrm{O}$ and other inhalation anesthetics may reinforce neurotoxicity $[10,11]$, questions have been raised regarding the safety of $\mathrm{N}_{2} \mathrm{O}$ in pediatric anesthesia.

Therefore, we sought to investigate the incidence of EA when excluding $\mathrm{N}_{2} \mathrm{O}$, resulting in an increased dose of sevoflurane and higher residual sevoflurane concentration during emergence compared to that with concomitant use of $\mathrm{N}_{2} \mathrm{O}$. The purpose of this study was to compare the incidence of EA, emergence time and fentanyl dosage in the postanesthesia care unit (PACU) in patients undergoing tonsillectomy and adenoidectomy using sevoflurane with or without $\mathrm{N}_{2} \mathrm{O}$ for general anesthesia.

\section{Materials and Methods}

This study was approved by the Institutional Review Board and registered at the UMIN clinical trials registry (R000012583). A total of 80 patients aged 3-10 years with American Society of Anesthesiologists physical status I or II undergoing tonsillectomy and adenoidectomy were enrolled in this study. Investigators explained the purpose and methods of this trial to each caregiver the day before the surgery and obtained written informed consent. Patients who were obese with body mass index (BMI) $>30 \mathrm{~kg} / \mathrm{m}^{2}$, had a history of hypersensitivity to fentanyl, had communication disorders due to developmental disabilities, articulation disorders, or other disorders, or who had a history of epilepsy were excluded. We randomly assigned the patients to the sevoflurane with $\mathrm{N}_{2} \mathrm{O}$ group (Group $\mathrm{N}, \mathrm{n}=40$ ) or the sevoflurane alone group (Group S, $\mathrm{n}=40$ ) using a computergenerated random number table.

All patients received premedication with $0.01 \mathrm{mg} / \mathrm{kg}$ of intramuscular (IM) atropine 30 minutes before the surgery. The anesthesiologist assessed the level of anxiety using a 5-point scale (calm, anxious, crying, crying inconsolably, restlessness) just before entering the operation room, and excluded the children who expressed severe anxiety corresponding to the levels of crying inconsolably or restlessness. Once patients entered the operating room, vital signs including blood pressure, pulse rate, electrocardiogram and oxygen saturation were measured, and the sensor strip of bispectral index (BIS) (Aspect Medical Systems, Norwood, USA) was attached to the forehead.

Anesthesia was induced with intra-venous administration of thiopental $5 \mathrm{mg} / \mathrm{kg}$, rocuronium $0.6 \mathrm{mg} / \mathrm{kg}$ and ketorolac 0.5 $\mathrm{mg} / \mathrm{kg}$, and following mask ventilation with 3 vol\% sevoflurane in $\mathrm{O}_{2}$ at $6 \mathrm{~L} / \mathrm{min}$ for 3 minutes. After intubation, anesthesia was maintained with $1-3 \mathrm{vol} \%$ sevoflurane in $3 \mathrm{~L} / \mathrm{min}$ of a mixture of $50 \% \mathrm{~N}_{2} \mathrm{O}$ and $\mathrm{O}_{2}\left(\mathrm{FiO}_{2} 0.5\right)$ in Group N, and with $2-4$ vol\% sevoflurane in $3 \mathrm{~L} / \mathrm{min}$ of a mixture of $50 \% \mathrm{O}_{2}$ and medical air $\left(\mathrm{FiO}_{2} 0.5\right)$ in Group S. The BIS monitoring (BIS VISTA a bispectral index monitor, Aspect Medical Systems, Norwood, USA) was applied to all patients and the concentration of sevoflurane was adjusted to achieve the BIS value of 40-60 in both groups.

At the end of the surgery, the end-tidal sevoflurane concentration (Et Sevo) (\%) and the BIS value were recorded. All inhalation anesthetics were discontinued simultaneously and 6 $\mathrm{L} / \mathrm{min}$ of $\mathrm{O}_{2}$ was supplied in both groups. Emergence times were measured from the time of the discontinuation of inhalation anesthetics to recovery of self-respiration, to eye-opening, and to extubation. When patients recovered self-respiration, Et Sevo was recorded and patients received pyridostigmine $0.25 \mathrm{mg} / \mathrm{kg}$ and glycopyrrolate $0.01 \mathrm{mg} / \mathrm{kg}$ for reversal of muscle relaxation. The patients were extubated when they had sufficiently recovered self-respiration and muscular strength.

EA and pain scores in the PACU were evaluated by an anesthesiologist who was not involved in the anesthesia using the Pediatric Anesthesia Emergence Delirium (PAED) scale [12]. The PAED scale assesses 5 items (1, makes eye contact with the caregiver; 2, actions are purposeful; 3 , aware of surroundings; 4 , restless; 5 , inconsolable) on a 5 -point scale that ranges from 0 to 4 (for Items 1, 2 and 3, $4=$ not at all, $3=$ just a little, $2=$ quite a bit, $1=$ very much, $0=$ extremely; for Items 4 and 5, $0=$ not at all, 1 = just a little, 2 = quite a bit, 3 = very much, $4=$ extremely). The score for each item was added to obtain the total PAED scale score, with a higher total score indicating more severe EA $(0=$ no emergence agitation; $20=$ extreme emergence agitation). Those whose score was 10 or more were defined as having EA. The pain score was evaluated using the modified Children's Hospital of Eastern Ontario Pain Scale (CHEOPS) (Table 1), 
which assigns 0-2 points to each of 5 items (Cry, Facial, Verbal, Torso, Legs) and is expressed as the sum of all items (0-10 points). Patients with a PAED scale score of 10 or more or with a modified CHEOPS score of 7 or more were given IV fentanyl 1 $\mu \mathrm{g} / \mathrm{kg}$. Those who had less than 10 on the PAED scale score and less than 7 on the modified CHEOPS but complained of pain received fentanyl $0.5 \mu \mathrm{g} / \mathrm{kg}$.

The number of subjects was determined as follows: in a previous study, the incidence of EA in children after general anesthesia using sevoflurane and $\mathrm{N}_{2} \mathrm{O}$ (Group $\mathrm{N}$ ) was 50\% [13]. Assuming that the difference in EA incidence was $30 \%$ compared to Group $S$, the required number of subjects was 36 for each group $(\alpha=0.05$, power $=0.8)$. Considering a $10 \%$ chance of withdrawal, we determined to include 40 subjects per group, resulting in a total of 80 subjects.

Table 1. Modified CHEOPS*

\begin{tabular}{ll}
\hline \multicolumn{1}{c}{ Observed behavior } & Score \\
\hline Cry & \\
No cry & 0 \\
Crying, moaning & 1 \\
$\quad$ Scream & 2 \\
Facial & \\
$\quad$ Smiling & 0 \\
$\quad$ Composed & 1 \\
$\quad$ Grimace & 2 \\
Verbal & \\
$\quad$ Positive & 0 \\
$\quad$ None or other complaints & 1 \\
$\quad$ Pain complaint & 2 \\
Torso & \\
$\quad$ Neutral & 0 \\
Shifting, tense, upright & 1 \\
Restrained & 2 \\
Legs & \\
$\quad$ Neutral & 0 \\
Kick, squirm, drawn up & 1 \\
Restrained & 2 \\
\hline
\end{tabular}

*Modified Children's Hospital of Eastern Ontario Pain Scale. Pain score was assessed using the Modified CHEOPS. There are 5 items (Cry, Facial, Verbal, Torso, Legs) and each item scores from 0 to 2. Pain score is sum of the score of the 5 items, and therefore ranges from 0 to 10.
The statistical analysis was performed using SPSS software (SPSS 12.0KO for Windows, SPSS Inc., USA). The results were expressed as mean \pm SD (standard deviation), number $(n)$, or percentage (\%). For comparison of the data, we used the $\chi^{2}$-test for gender and Student's t-test for age, height, weight, body mass index (BMI), Et Sevo, BIS value and emergence time. The incidences of EA in the PACU were compared using the $\chi^{2}$-test; the pain scores were compared using the Mann Whitney U-test, and Student's t-test was used for the comparison of fentanyl dosage. For all tests, a $\mathrm{P}$ value $<0.05$ was considered statistically significant.

\section{Results}

Out of 80 pediatric patients, 6 patients who preoperatively expressed anxiety corresponding to the level of crying inconsolably or behaved uncooperatively were excluded. Finally, 74 patients were included. There were no significant differences between the two groups with respect to age, gender, height, weight and BMI (Table 2).

Et Sevo at the end of surgery was significantly higher in Group S compared to Group N $(2.3 \pm 0.6 \%$ vs. $1.9 \pm 0.3 \%$; $\mathrm{P}<$ $0.001)$, but the BIS value at the end of surgery did not significantly differ between the two groups $(\mathrm{P}=0.18)$. There were no significant differences in the emergence time, including times to recovery of self-respiration, to eye-opening, and to extubation, as well as Et Sevo at recovery of self-respiration between the two

Table 2. Demographic Data

\begin{tabular}{lccc}
\hline & $\begin{array}{c}\text { Group N } \\
(\mathrm{n}=36)\end{array}$ & $\begin{array}{c}\text { Group S } \\
(\mathrm{n}=38)\end{array}$ & P value \\
\hline Sex $(\mathrm{M} / \mathrm{F})$ & $23 / 13$ & $26 / 12$ & 0.81 \\
Age $(\mathrm{yr})$ & $6.5 \pm 1.3$ & $7.1 \pm 1.6$ & 0.80 \\
Weight $(\mathrm{kg})$ & $24.7 \pm 5.6$ & $27.2 \pm 7.9$ & 0.12 \\
Height $(\mathrm{cm})$ & $120.5 \pm 10.7$ & $123.8 \pm 10.8$ & 0.20 \\
Body mass index $\left(\mathrm{kg} / \mathrm{m}^{2}\right)$ & $16.8 \pm 2.1$ & $17.4 \pm 2.9$ & 0.34 \\
\hline
\end{tabular}

Values are mean \pm SD or number of patients. Group N: sevoflurane with $\mathrm{N}_{2} \mathrm{O}$ group, Group S: sevoflurane alone group.

Table 3. Emergence Profiles

\begin{tabular}{lccc}
\hline & Group N (n=36) & Group S (n=38) & P value \\
\hline Et Sevo (\%) at the end of surgery & $1.9 \pm 0.3$ & $2.3 \pm 0.6^{*}$ & $<0.001$ \\
Bispectral index (BIS) at the end of surgery & $50.2 \pm 5.1$ & $48.4 \pm 6.1$ & 0.18 \\
Et Sevo (\%) at recovery of self-respiration & $0.2 \pm 0.1$ & $0.2 \pm 0.1$ & 0.21 \\
Recovery of self-respiration (min) & $10.9 \pm 3.4$ & $1.2 \pm 2.0$ & 0.73 \\
Eye opening (min) & $15.5 \pm 3.7$ & $18.7 \pm 10.1$ & 0.09 \\
Extubation (min) & $14.4 \pm 3.1$ & $14.8 \pm 2.8$ & 0.58 \\
\hline
\end{tabular}

Values are mean \pm SD. Group N: sevoflurane with $\mathrm{N}_{2} \mathrm{O}$ group, Group S: sevoflurane alone group. Et Sevo: mean end-tidal sevoflurane concentration. Recovery of self-respiration: mean time to recovery of self-respiration from the discontinuation of anesthetics. Eye opening: mean time to eye opening from the discontinuation of anesthetics. Extubation: mean time to extubation from the discontinuation of anesthetics. ${ }^{*} \mathrm{P}<0.05$ compared to group $\mathrm{N}$. 
Table 4. PAED Scale, Pain Score and Rescue Fentanyl Consumption in PACU

\begin{tabular}{lrrr}
\hline & $\begin{array}{r}\text { Group N } \\
(\mathrm{n}=36)\end{array}$ & $\begin{array}{r}\text { Group S } \\
(\mathrm{n}=38)\end{array}$ & P value \\
\hline PAED scale $\geq 10, \mathrm{n}(\%)$ & $10(27.8)$ & $15(39.5)$ & 0.33 \\
Pain score & $5(1-9)$ & $5(0-9)$ & 0.44 \\
Rescue fentanyl consumption $(\mu \mathrm{g} / \mathrm{kg})$ & $0.4 \pm 0.5$ & $0.5 \pm 0.5$ & 0.37 \\
\hline
\end{tabular}

Group N: sevoflurane with $\mathrm{N}_{2} \mathrm{O}$ group, Group S: sevoflurane alone group. PAED scale: Pediatric Anesthesia Emergence Delirium scale (from 0 to 20 ). PAED scale $\geq 10$ was defined as occurrence of emergence agitation and is expressed as number of patients (\%). Pain score was assessed using Modified CHEOPS (Children's Hospital of Eastern Ontario Pain Scale), from 0 to 10 (Table 1 ) and is expressed as median value (range). Rescue fentanyl consumption values are mean $\pm \mathrm{SD}$.

groups (for both groups, $0.2 \pm 0.1 \%$ ) (Table 3 ).

The percentage of patients who showed EA in the PACU with a PEAD scale $\geq 10$ was $27.8 \%(n=10)$ in Group $\mathrm{N}$ and $39.5 \%$ $(\mathrm{n}=15)$ in Group $\mathrm{S}$, which were not statistically significantly different $(\mathrm{P}=0.33)$. The pain scores measured by the modified CHEOPS as well as the fentanyl dosages used in the PACU were not significantly different between the two groups (Table 4).

\section{Discussion}

In this study of children undergoing tonsillectomy and adenoidectomy, anesthesia using sevoflurane with or without $\mathrm{N}_{2} \mathrm{O}$ did not show a significant difference in emergence time. Although the incidence of EA was $12 \%$ higher in children using sevoflurane alone, this was not statistically significant. There were no differences in the postoperative pain scores and fentanyl dosage.

Recent studies suggested sevoflurane itself as a possible causal factor of EA [7,14]. Sevoflurane is known to act on $\gamma$-aminobutyrateA $\left(\mathrm{GABA}_{\mathrm{A}}\right)$ receptors, similar to benzodiazepine, but the mechanism and treatment of EA are still unclear $[5,7,14]$. Shibata et al. [6] suggested that residual sevoflurane might be the contributing factor of EA and that decreasing the concentration of residual sevoflurane at the recovery of self-respiration by supplying $\mathrm{N}_{2} \mathrm{O}$ after the discontinuation of sevoflurane during emergence could reduce the incidence of emergency agitation. In this study, we concurrently discontinued all of the inhalation anesthetics at the end of the surgery and Et Sevo at the end of the surgery was lower in the sevoflurane with $\mathrm{N}_{2} \mathrm{O}$ group compared to sevoflurane alone group, but time to recovery of self-respiration and Et Sevo at recovery of self-respiration did not differ in the two groups. Our finding that there was no difference in the incidence of EA between the two groups may be explained by the lack of difference in Et Sevo at recovery of self-respiration (Table 3). As a result, a decreased concentration of sevoflurane dosage due to concomitant use of $\mathrm{N}_{2} \mathrm{O}$ could not induce a statistically significant reduction of EA compared to the use of sevoflurane alone.

$\mathrm{N}_{2} \mathrm{O}$ is a NMDA receptor antagonist, similar to ketamine. According to recent animal studies, $\mathrm{N}_{2} \mathrm{O}$ is likely to damage developing brain cells $[8,9]$, and concomitant use of an inhalation anesthetic and $\mathrm{N}_{2} \mathrm{O}$ can cause extensive nerve injuries in the brain [10]. These nerve damages have been reported to lead to hippocampal synaptic dysfunction, resulting in persistent memory and learning disorders [11]. Moreover, it has been found that these damages occurred in a dose-dependent manner and worsened with combination of the agents $[10,15]$. Additionally, earlier and repeated exposure to anesthesia is likely to increase the risk of neurodevelopmental disability $[15,16]$. Although the clinical application of these results remains controversial, the use of $\mathrm{N}_{2} \mathrm{O}$ should be carefully considered in pediatric anesthesia, and furthermore, efforts should be made to develop alternative anesthetic techniques. In particular, the use of $\mathrm{N}_{2} \mathrm{O}$ alone in the absence of surgical stimuli [6] is considered not advisable because it prolongs exposure to $\mathrm{N}_{2} \mathrm{O}$.

Based on a previous study [13], we expected that the incidence of EA would be about $50 \%$ in sevoflurane with $\mathrm{N}_{2} \mathrm{O}$ group, but in the present study the actual incidence was much lower in both groups (Group N, 28\%; Group S, 40\%). This discrepancy may be due to the effect of ketorolac $0.5 \mathrm{mg} / \mathrm{kg}$, which was given with the anesthetic agents for induction. Assuming that the use of sevoflurane alone could not control surgical pain and subsequent hemodynamic instability, we administered ketorolac to all patients in both groups. Several studies have reported that the use of NSAIDs (non-steroidal anti-inflammatory drugs) including ketorolac reduced EA with its analgesic effect [17-19]. Admitting that it is not easy to distinguish EA from pain response in children, it is well known that inappropriate postoperative pain control increases the incidence of EA [4]. The analgesic effect of ketorolac may also explain the lack of a significant difference in the incidence of EA between the two groups in this study. Given that the PAED scale used in this study includes a pain scale, it could be speculated that the effect of ketorolac led to the lower overall incidence of EA and narrowed differences between the groups.

Since the incidence of EA varies widely from 2 to $80 \%$ with anesthetic techniques and evaluation criteria [20], remarkable differences can be observed even in the same study depending on the criteria selected (e.g. 33 and 80\%) [21]. Shrout and Fleiss [22] indicated that errors in measurement substantially affected statistical analysis and interpretation. In 2004, the PAED sale [12], which was developed by Sikich and Lerman in order to minimize errors, was introduced in Anesthesiology. The evaluation methods of EA vary across studies. We used the PAED scale, but Shibata et al. [6] selected the 3-point scale. Choi et al. [23], who examined the effect of remifentanil on EA, used the 
4-point scale, and Na et al. [13] employed both the 4-point scale and PAED scale. In the present study, the lack of a significant difference in the incidence of EA between the two groups may actually imply no difference, but we cannot exclude the possibility of the impact of different evaluation methods on the recorded incidences.

In conclusion, this study of children undergoing tonsillectomy and adenoidectomy, with administration of ketorolac for hemodynamic stability, demonstrated that anesthesia using sevoflurane alone resulted in significantly higher Et Sevo at the end of the surgery compared to sevoflurane anesthesia with concomitant use of $\mathrm{N}_{2} \mathrm{O}$. However, no significant differences were observed in emergence time and Et Sevo during emergence as well as the incidence of EA, pain score and fentanyl dosage in the PACU.

\section{References}

1. Aono J, Ueda W, Mamiya K, Takimoto E, Manabe M. Greater incidence of delirium during recovery from sevoflurane anesthesia in preschool boys. Anesthesiology 1997; 87: 1298-300.

2. Uezono S, Goto T, Terui K, Ichinose F, Ishguro Y, Nakata Y, et al. Emergence agitation after sevoflurane versus propofol in pediatric patients. Anesth Analg 2000; 91: 563-6.

3. Lapin SL, Auden SM, Goldsmith LJ, Reynolds AM. Effects of sevoflurane anaesthesia on recovery in children: a comparison with halothane. Paediatr Anaesth 1999; 9: 299-304.

4. Vlajkovic GP, Sindjelic RP. Emergence delirium in children: many questions, few answers. Anesth Analg 2007; 104: 84-91.

5. Kim JH. Mechanism of emergence agitation induced by sevoflurane anesthesia. Korean J Anesthesiol 2011; 60: 73-4.

6. Shibata S, Shigeomi S, Sato W, Enzan K. Nitrous oxide administration during washout of sevoflurane improves postanesthetic agitation in children. J Anesth 2005; 19: 160-3.

7. Yasui Y, Masaki E, Kato F. Sevoflurane directly excites locus coeruleus neurons of rats. Anesthesiology 2007; 107: 992-1002.

8. Haberny KA, Paule MG, Scallet AC, Sistare FD, Lester DS, Hanig JP, et al. Ontogeny of the N-methyl-D-aspartate (NMDA) receptor system and susceptibility to neurotoxicity. Toxicol Sci 2002; 68: 9-17.

9. Ikonomidou C, Bosch F, Miksa M, Bittigau P, Vöckler J, Dikranian K, et al. Blockade of NMDA receptors and apoptotic neurodegeneration in the developing brain. Science 1999; 283: 70-4.

10. Jevtovic-Todorovic V, Hartman RE, Izumi Y, Benshoff ND, Dikranian K, Zorumski CF, et al. Early exposure to common anesthetic agents causes widespread neurodegeneration in the developing rat brain and persistent learning deficits. J Neurosci 2003; 23: 876-82.

11. Shu Y, Patel SM, Pac-Soo C, Fidalgo AR, Wan Y, Maze M, et al. Xenon pretreatment attenuates anesthetic-induced apoptosis in the developing brain in comparison with nitrous oxide and hypoxia. Anesthesiology 2010; 113: 360-8.

12. Sikich N, Lerman J. Development and psychometric evaluation of the pediatric anesthesia emergence delirium scale. Anesthesiology 2004; 100: $1138-45$.

13. Na HS, Song IA, Hwang JW, Do SH, Oh AY. Emergence agitation in children undergoing adenotonsillectomy: a comparison of sevoflurane vs. sevoflurane-remifentanil administration. Acta Anaesthesiol Scand 2013; 57: 100-5.

14. Jöhr M. Postanaesthesia excitation. Paediatr Anaesth 2002; 12: 293-5.

15. Scallet AC, Schmued LC, Slikker W Jr, Grunberg N, Faustino PJ, Davis H, et al. Developmental neurotoxicity of ketamine: morphometric confirmation, exposure parameters, and multiple fluorescent labeling of apoptotic neurons. Toxicol Sci 2004; 81: 364-70.

16. Loepke AW, Soriano SG. An assessment of the effects of general anesthetics on developing brain structure and neurocognitive function. Anesth Analg 2008; 106: 1681-707.

17. Davis PJ, Greenberg JA, Gendelman M, Fertal K. Recovery characteristics of sevoflurane and halothane in preschool-aged children undergoing bilateral myringotomy and pressure equalization tube insertion. Anesth Analg 1999; 88: 34-8.

18. Rampersad S, Jimenez N, Bradford H, Seidel K, Lynn A. Two-agent analgesia versus acetaminophen in children having bilateral myringotomies and tubes surgery. Paediatr Anaesth 2010; 20: 1028-35.

19. Sutters KA, Levine JD, Dibble S, Savedra M, Miaskowski C. Analgesic efficacy and safety of single-dose intramuscular ketorolac for postoperative pain management in children following tonsillectomy. Pain 1995; 61: 145-53.

20. Dahmani S, Stany I, Brasher C, Lejeune C, Bruneau B, Wood C, et al. Pharmacological prevention of sevoflurane- and desflurane-related emergence agitation in children: a meta-analysis of published studies. Br J Anaesth 2010; 104: 216-23.

21. Cravero J, Surgenor S, Whalen K. Emergence agitation in paediatric patients after sevoflurane anaesthesia and no surgery: a comparison with halothane. Paediatr Anaesth 2000; 10: 419-24.

22. Shrout PE, Fleiss JL. Intraclass correlations: uses in assessing rater reliability. Psychol Bull 1979; 86: 420-8.

23. Choi HR, Cho JK, Lee S, Yoo BH, Yon JH, Kim KM. The effect of remifentanil versus N(2)O on postoperative pain and emergence agitation after pediatric tonsillectomy/adenoidectomy. Korean J Anesthesiol 2011; 61: 148-53. 